\section{Application of Light-emitting Diodes and the Effect of Light Quality on Horticultural Crops: A Review}

\author{
Liang Zheng, Huaming He, and Weitang Song \\ College of Water Resources and Civil Engineering, China Agricultural \\ University, Beijing 100083, China
}

Additional index words. light-emitting diodes, photosynthesis, plant growth, light quality

\begin{abstract}
Plant growth and development relies on light and is influenced by light. Lightemitting diode (LED) technology is nowadays providing the possibility for regulating plant growth and development by modifying light spectral composition. Many researches have been carried out to figure out the effects of light quality on various aspects of plant behaviors, including plant morphology, physiology, and biochemistry. In this review, we summarized those research outputs, in order to give suggestion of light quality application for both research and production purposes, in the field of productional yield, productional quality for horticultural plants including vegetables or ornamentals in difference with cultivation goals.
\end{abstract}

Light is one of the most important environmental factors that influence plant growth and development. Light energy is captured by higher plants during photosynthesis, whereas light signaling plays primary roles in plant morphogenesis (Abidi et al., 2013; Jiao et al., 2007). Changes in light quality, intensity, and duration cause responses at anatomical, physiological, and biochemical levels and, thus, influence plant morphology and functioning (Haliapas et al., 2008). The development of LED technology opens the possibility for photosynthetic optimization and plant physiology regulation by manipulating light characteristics (Kim et al., 2019; Mitchell et al., 2012). In addition, LED is an energy-saving solution in replacement of traditional lamps in artificial lighting of controlled environmental conditions, especially the primary production phases with relatively small plant dimensions and reduced space/plant requirement (Goto, 2012; Nelson and Bugbee, 2014).

\section{LEDs and Conventional Lighting in Horticulture}

Horticultural production with controlled environments is one of the most energyintensive systems in agricultural production (Tähkämö and Dillon, 2014). Artificial lighting is one of the most important energy consumption areas (for instance, the energy consumption of the Dutch greenhouse sector was $37 \%$ electricity and $63 \%$ heat in 2013, Dieleman et al., 2016), although it allows year-round production and quality increase independent of the climatic condition and geographic location.

Conventional lighting equipment such as fluorescent tubes and high-pressure so-

Received for publication 5 Apr. 2019. Accepted for publication 25 June 2019.

L.Z. is the corresponding author. E-mail: zhengliang @cau.edu.cn. dium (HPS) lamps were widely used, thanks to their relatively high energy conversion efficiency and economical affordability (Riikonen et al., 2016). However, lamps such as HPS lamps emit broad-spectrum radiation that mainly fall in the orange-red region $(550-650 \mathrm{~nm})$ and less in the blue spectra between 400 and $500 \mathrm{~nm}$ (Islam et al., 2012) that are also strongly absorbed by the photosynthetic pigments. Besides, HPS lamps produce much heat, which account for $25 \%$ of the electrical energy input that is converted to IR radiation (Nelson and Bugbee, 2014). The heat generated helps in greenhouse heating; yet, it limits the possibility for supplying light close to plants when used in multilayer vertical farming and with interlighting strategies.

LED was introduced in plant cultivation in the 2000s (Piovene et al., 2015) and is nowadays widely used in plant factories as a more efficient light source to reduce the high electricity costs of lighting (Goto, 2012), and because of its advantages over traditional forms (D'Souza et al., 2015), such as small size, durability, long lifetime, cool emitting temperature, and the option to select specific wavelengths for a targeted plant response. Indeed, researches to develop tailored light strategies, especially for horticultural production in controlled environments, have strongly increased in the recent years.

\section{Light Absorption and Plant Photosynthesis}

Chlorophylls, carotenoids, and anthocyanins are three major light-absorbing pigments in higher plants. Plants use light wavelengths within the range from 400 to $700 \mathrm{~nm}$ (photosynthetically active radiation) for photosynthetic activity (Davis and Burns, 2016). McCree (1971) quantified the spectral absorption of several species and indicated that red wavelengths (600 to $700 \mathrm{~nm})$ are most effi- ciently absorbed by chlorophyll. Chlorophyll a has its absorption peaks at 430 and $665 \mathrm{~nm}$, whereas chlorophyll $\mathrm{b}$ has its absorption peaks at 453 and $642 \mathrm{~nm}$ (Sager and McFarlane, 1997). The carotenoids absorb strongly the blue light region, with maximum absorption at 448 and $452 \mathrm{~nm}$ (Wright and Shearer, 1984) (Fig. 1). Anthocyanins are known to prevent photoinhibition and photodamage by absorbing excessive radiation that would otherwise be absorbed by chloroplast pigments (Takahashi and Badger, 2011). Therefore, blue and red LEDs are widely accepted as the light source. The effects of light quality and intensity on horticultural traits and the increased availability of narrow-bandwidth light sources present an opportunity to exploit the knowledge of light-sensory circuitry to custom-blend light regimens that drive plant responses to match market demands.

\section{Photoreceptors}

Light affects virtually all aspects of plant growth and development from germination to aspects of vegetative morphology, reproductive activity and floral initiation, and entrainment of circadian rhythms (Galvão and Fankhauser, 2015). In response to the complex light environment, plants use multiple photoreceptors that are sensitive to specific wavelength to monitor light signal and to regulate plant behavior (Mawphlang and Kharshiing, 2017). The most important photoreceptors identified so far include the phytochromes (phy), which absorb primarily the red/far-red spectrum (600-800 nm) (Furuya and Schäfer, 1996); the cryptochromes (cry), which absorb specifically blue/ultraviolet-A light (350-500 nm); the phototropins (phot) (Cashmore et al., 1999); and the ultraviolet-B absorbing photoreceptor UVR8 (Rizzini et al., 2011) (Fig. 2).

Phytochrome. Phytochromes are the first identified light-sensing molecules in plants. Phytochromes are encoded by the PHYA$P H Y E$ small gene family in most plant species and control processes of the entire plant life cycle (Galvão and Fankhauser, 2015). There are five types of phytochromes (phyA, phyB, phyC, phyD, and phyE) currently identified in the dicot model plant Arabidopsis (Fankhauser and Chory, 1997) and three types (phyA, phyB, and phyC) in the monocot plant rice (Gu et al., 2011). All plant phytochromes contain two domains: an $\mathrm{N}$-terminal domain and a C-terminal domain. Phytochromes influence plant developmental performance, including gravitropism, phototropism, and the shade-avoidance response (Brouwer et al., 2014). There are two phytochrome forms: the red light-absorbing form $\left(\mathrm{P}_{\mathrm{r}}\right)$, which is inactive, and the far-redabsorbing form $\left(\mathrm{P}_{\mathrm{fr}}\right)$, which is active. Photo-transformation between the two forms happens when it is exposed to either red or far-red light; illuminating dark adapted tissues with red light converts phytochromes from $P_{r}$ to $P_{f r}$, whereas with far-red light illumination the reverse happens, restoring $P_{r}$ (Quail, 1997). It is associated with a 


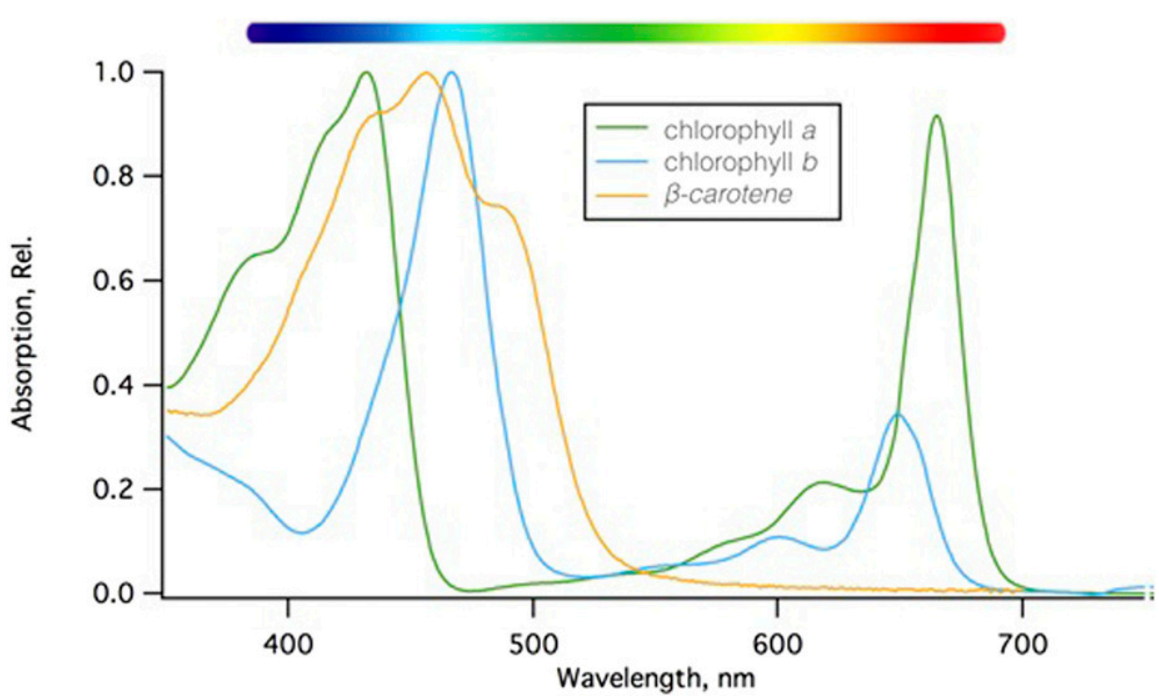

Fig. 1. Absorption spectra of the major chlorophyll and carotenoid pigments in plants (Johnson, 2016) Chlorophylls absorb light energy mainly in the red and blue parts of the visible spectrum, whereas carotenoids absorb blue and green wavelengths.

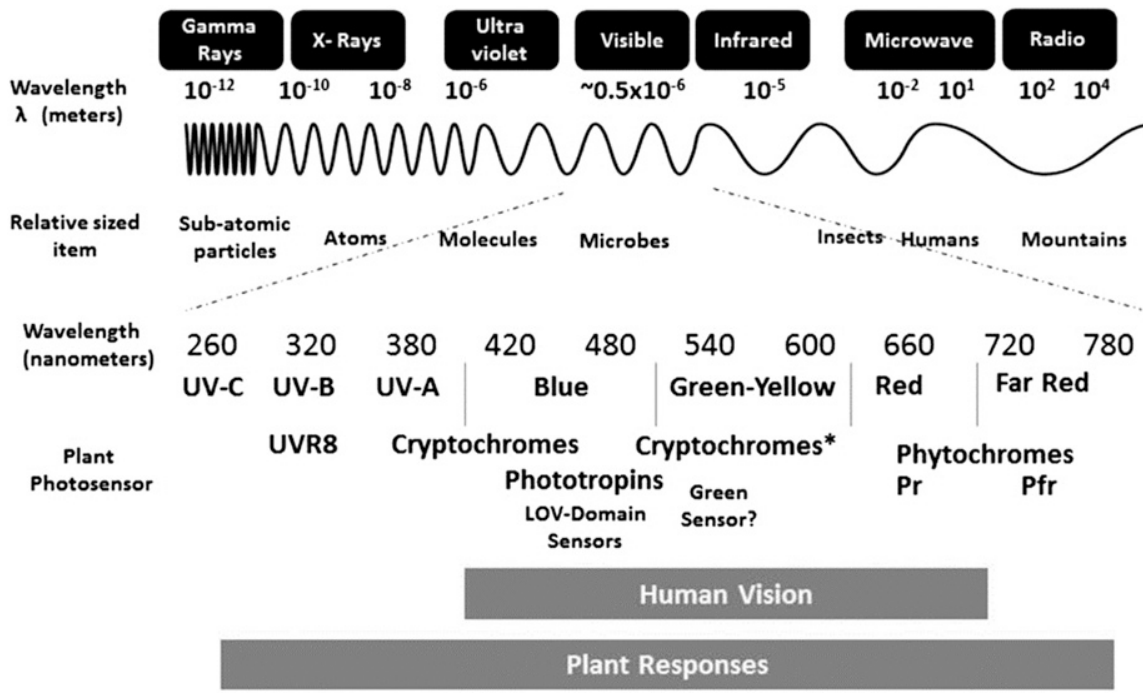

Fig. 2. The relative distribution of electromagnetic energies and the wavelengths that discretely interact with plant photoreceptors (Folta and Carvalho, 2015).

structural and conformational absorption peak change between $666 \mathrm{~nm}\left(\mathrm{P}_{\mathrm{r}}\right)$ and $730 \mathrm{~nm}\left(\mathrm{P}_{\mathrm{fr}}\right)$ (Sullivan and Deng, 2003). Photo-transformation between the $\mathrm{P}_{\mathrm{r}}$ and $\mathrm{P}_{\mathrm{fr}}$ forms is efficiently achieved not only by red light, but also by lights of other wavelengths ranging from ultraviolet $(300 \mathrm{~nm})$ to far-red $(800 \mathrm{~nm})$, but with far less efficiency.

Cryptochrome. Cryptochromes are flavintype photoreceptors that perceive ultravioletA and blue light (370 and $450 \mathrm{~nm}$ ). The first sequence of a blue-light receptor, cryptochrome1 (CRY1), was reported by Ahmad and Cashmore (1993). Cryptochromes in Arabidopsis genome have three subfamilies: CRY1, CRY2, and CRY3 (Lin and Shalitin, 2003), whereas monocot rice possesses four CRY genes: OsCRY1a, OsCRY1b, OsCRY2, and OsCRY-DASH (Hirose et al., 2006). Most plant cryptochromes have two domains: the light-dependent modulation of transcription (the CRY-CIBs pathway) and the lightdependent suppression of protein degradation (the CRY-SPA1/COP1 pathway) (Liu et al., 2012).

Phototropin. Phototropins are a distinct class of photoreceptors that mediate phototropic responses of ultraviolet-A/blue light (320-500 nm) (Wang et al., 2013). Arabidopsis has two phototropins designated phot 1 and phot2 (Briggs and Christie, 2002). Phototropins contain two LOV domains: LOV1 and LOV2, which regulate responses to light, oxygen, or voltage. Each of the LOV domains binds a flavin mononucleotide as a chromophore to make the holoprotein. Phototropins control a wide range of plant responses, such as stomatal opening, phototropism (bending toward light), chloroplast movement (Kasahara et al., 2002), leaf flattening (de Carbonnel et al., 2010), and deetiolation (Casal, 2000).

UVR8. UVR8 is a seven-bladed $\beta$ propeller protein, which is originally identified in Arabidopsis mutants that are hypersensitive to ultraviolet-B (Kliebenstein et al., 2002). Ultraviolet-B light promotes the accumulation of UVR8 in the nucleus by regulating the redistribution in the cells but does not increase its abundance (Kaiserli and Jenkins, 2007). In the nucleus, UVR8 associates with the chromatin of ultravioletB-responsive genes, such as the promoter region of HY5, suggesting that UVR8 may be directly involved in transcriptional regulation (Brown et al., 2005).

It is through complex coordination of these photoreceptors that plants respond to the light environment with both physiological and morphological changes. Phytochrome and UVR8 cooperate to optimize plant growth and defense in patchy canopies (Mazza and Ballaré, 2015). phyA or phyB are also reported to be involved in some blue light responses in coordination with the cryptochromes (Luesse et al., 2010). The repression of hypocotyl gravitropism responses to very low irradiance blue light $\left(0.1-0.7 \mu \mathrm{mol} \cdot \mathrm{m}^{-2} \cdot \mathrm{s}^{-1}\right)$ is regulated by phyA in Arabidopsis (Lariguet and Fankhauser, 2004). Also, phyA irreversibly triggers seed germination upon irradiation under extremely low irradiance ultraviolet-A and blue light, whereas phyB controls the photoreversible effects of low fluency (Shinomura et al., 1996).

\section{Impact of Light Quality on Plants}

Plant productivity is not only influenced by light quantity through photosynthetic activity by which carbohydrates are synthesized using the energy of light, but also affected by the qualitative characteristics of light that strongly influence plant growth, morphology, physiology, and phytochemical accumulation.

The influence of light quality on plant growth. LED systems are able to provide multiple light spectra for horticultural production. As described earlier, a combination of red and blue light is commonly used to 
enhance the absorption of photosynthetic pigments. The beneficial effects of additional blue photons in plant growth have been demonstrated in numerous studies. In the production of leafy vegetables such as lettuce, radish, and spinach, combined red/blue light was beneficial for accumulating biomass (Yorio et al., 2001). In fruit production, Samuoliene et al. (2010) reported that additional blue light resulted in bigger fruits with higher sugar content in strawberries, whereas the use of red light alone inhibited flowering (Yoshida et al., 2012). In greenhouse production, Kaiser et al. (2019) supplied tomato with different ratios of blue light $(0,6,12$, and $24 \%$, together with red light) with sunlight as the background, which resulted in an increase in total biomass and fruit number, with the increase in blue light percentage to an optimum (12\%). Although the necessity of blue light is commonly accepted, the optimal $\mathrm{red} / \mathrm{blue}$ ratio is species and genotype dependent. There were inter- and intraspecific differences with respect to the red/blue ratio. For example, in lettuce, leaf photosynthetic capacity and photosynthetic rate increase with decreasing $\mathrm{R} / \mathrm{B}$ ratio, which is associated with increasing stomatal conductance $\left(g_{\mathrm{S}}\right)$, along with promoted shoot dry weight (Wang et al., 2016). However, Son and Oh (2013) reported a decrease in growth rate in other lettuce cultivars with the increase in blue and ultraviolet-A light, which was attributed to a difference in genotypes. In sweet basil and strawberry, the optimal spectra was observed at an $\mathrm{R} / \mathrm{B}$ ratio of 0.7 based on a range of analyses (morphological, physiological, and biochemical elements) (Piovene et al., 2015) whereas Folta and Childers (2008) observed the greatest growth rate of strawberry plants under $34 \%$ blue light. Besides, the growth rate of rapeseed increased with a higher blue light percentage (range from $0 \%$ to $75 \%$ ) ( $\mathrm{Li}$ et al., 2013). Naznin et al. (2019) investigated the effect of $\mathrm{R} / \mathrm{B}$ ratio on lettuce, spinach, kale, basil, and pepper and concluded that additional blue light with red light is essential to promote growth, pigmentation, and antioxidant content of these vegetable plants, although the optimal ratio is species dependent. Besides, another disagreement is whether monochromatic blue light is positive or negative for normal development of plants. Whereas certain reports described inhibited photosynthetic rates and biomass accumulation under monochromatic blue light compared with $\mathrm{R} / \mathrm{B}$ combined or broad-spectrum light (Hamdani et al., 2019; Wang et al., 2016), others claimed that monochromatic blue induced the greatest biomass accumulation (Liu et al., 2014).

Photosynthesis. The role of photon flux density on photosynthesis has been studied in an array of plant species, resulting in lightdependent photosynthetic response curves at both the leaf and plant levels. The extent to which light quality affects photosynthesis is also potentially studied through its effects on the specific absorption spectrum of photosynthetic pigments, or the uptake of essential micronutrients to the photosynthetic electron transport chain (O'Carrigan et al., 2014).

The short-term response to light quality of photosynthetic $\mathrm{CO}_{2}$ fixation is wavelength dependent and changes rapidly. Spectrumdependent quantum yields are the highest for red wavelengths, whereas there is a reduction in blue wavelengths due to the partial absorption by non-photosynthetic pigments (Izzo et al., 2019). However, long-term application of red light induces an imbalance between the Photosystem I and II (Park and Runkle, 2018), which would, in turn, reduce the quantum yield. Indeed, monochromatic lights are unnatural lighting conditions for plants and reduce the photosynthetic rate in comparison with white light (Abidi et al., 2013; Hamdani et al., 2019). Therefore, combined multiple wavelengths are generally proposed in plant production systems. When exposing plants to blue light in addition to natural light, the photosynthetic activity increases with increasing blue photon proportion (Hogewoning et al., 2010; Kaiser et al., 2019; Wang et al., 2016).

Besides the direct photosynthetic activity, light quality regulates many other physiological aspects that indirectly affect photosynthesis. For example, blue light was suggested to have a higher efficiency in inducing stomatal opening in C3 plants (Hiyama et al., 2017; Liu et al., 2018), which is mediated by cryptochromes (Shimazaki et al., 2007). Blue spectra also affect the relocation of chloroplasts within the cells and, thus, influence light capture (Suetsugu and Wada, 2007). Chloroplasts accumulate at the cell surface to maximize light capture and photosynthetic ability in response to lowfluence blue light. By contrast, under higher fluence blue light, chloroplasts move to the opposite side to avoid photodamage (Kami et al., 2010), which is mediated by the phototropins (Kong and Wada, 2016).

Long-term exposure to a specific light condition modifies the plant anatomy and architecture, and chloroplast characteristics, thus indirectly affecting photosynthesis. Blue light was reported to be beneficial for chlorophyll accumulation and increasing the $\mathrm{Chl}$ $\mathrm{a} / \mathrm{b}$ ratio (Poudel et al., 2008). There are also reports that indicate that monochromatic blue light reduces chlorophyll content, while no effect was found in certain species (Abidi et al., 2013; Wang et al., 2015). At the molecular level, blue light upregulates the gene expression of $\mathrm{MgCH}$, GluTR, and $\mathrm{FeCH}$, which regulate the synthesis of enzymes involved in chlorophyll biosynthesis, and hence promotes chlorophyll accumulation (Lobiuc et al., 2017). By contrast, red light is not conducive to the formation of chlorophyll because of the reduction in the tetrapyrrole precursor 5-aminolevulinic acid (Sood et al., 2005; Tanaka and Tanaka, 2006). Leaf thickness, stomatal density, and palisade cell length are increased under blue light as compared with plants grown under red or green light (Shengxin et al., 2016; Wang et al., 2015). In cucumber grown under low radiations, illumination of chloroplasts with blue light resulted in a higher number of grana lamellae and more stacked thylakoid membranes than that with white or red light (Wang et al., 2014). Through the effects on leaf area, leaf orientation, and branching, light quality can influence light interception and, thus, indirectly affect photosynthetic capacity at the whole plant level.

Crop morphology. Spectral manipulation could maximize biomass production; however, especially in ornamental production, compact plants with fine morphological quality might be desired. There are several ways to regulate plant morphology, including irrigational manipulation, temperature profile altering, and using plant growth regulators (Davis and Burns, 2016). Nevertheless, the ability of LEDs to control the light spectrum provides the possibility to optimize plant morphology without chemical intervention.

Research on the photomorphogenic responses of blue light is ample. Blue light is known to inhibit stem elongation in many species; for instance, stem elongation of Chrysanthemum, Stevia rebaudiana, and Tripterospermum decreases as the blue light proportion increases (Heung et al., 2006; Yoneda et al., 2017; Zhiyu et al., 2007). This blue light is suggested to be an alternative for growth-retarding chemicals (Shimizu et al., 2006). Referring to the previous investigations, Poinsettias grown under red:blue light at $4: 1$ were $20 \%$ to $34 \%$ shorter than those grown under HPS (5\% blue) lamps (Islam et al., 2012). The addition of red light in the spectrum provided the greatest effect on reducing the plant height of roses and Chrysanthemum (Ouzounis et al., 2014), which is considered to be mediated by changes in the $\mathrm{R} / \mathrm{FR}$ ratio. Differences between plant morphological responses to red/far-red and blue light are associated with differences in the relative contributions of phytochromes and blue-sensitive photoreceptors (cryptochromes and phototropins) to the inhibition of stem extension. The R/B ratio, yet important, is not solely sufficient to control plant morphology. The absolute blue light intensity rather than the percentage of blue light was reported to control hypocotyl length and stem extension in tomato (Nanya et al., 2012). The light quality has a strong influence on leaf morphology; light treatments have been reported to cause leaf curling in many previous reports (Hughes, 2013; Oda et al., 2012; Ouzounis et al., 2014). In tomato, leaf lamina thickness was significantly reduced in R:B leaves, whereas in the plane leaf lamina thickness was significantly higher for $\mathrm{R}: \mathrm{B}$ than control leaves (Arena et al., 2016).

Stomatal morphology and $g_{\mathrm{S}}$. There is common agreement that shorter wavelength blue/ultraviolet-A light triggers the movement of guard cells through cryptochromes and phototropins, thus promoting the opening of stomata and generating a higher $g_{\mathrm{S}}$. Stomatal opening under red light is mainly caused by the decreased intercellular $\mathrm{CO}_{2}$ concentration, which is the result of mesophyll photosynthetic activity (Shimazaki et al., 2007); hence, the red light response 
of stomata requires a high light intensity. However, recent reports suggest that phyB plays an essential and direct role in inducing the stomatal opening in response to red light and that phyA might also participate in this regulation (Wang et al., 2010).

Light also affects the stomatal development: in general, an increase in light intensity results in an increase in stomatal density and stomatal index (Pillitteri and Torii, 2012). Stomatal development can be influenced by ultraviolet-B light; soybean leaves developed fewer stomata after ultraviolet-B exposure, which was considered to improve drought tolerance and photosynthetic performance (Gitz et al., 2005). Stoma routinely move in response to light to regulate water use and $\mathrm{CO}_{2}$ exchange between the plant and ambient atmosphere. The influence of light quality on the development and movement of stomata during the leaf growth induces long-term impacts on $g_{\mathrm{S}}$, photosynthetic performance, and water use efficiency.

Pigmentation and secondary metabolites. Primary metabolites are directly involved in growth, development, and reproduction. Yet, plants produce other compounds that are known as secondary metabolites. Secondary metabolites act to improve the adaptability of plants and help them acclimate to the changeable environment. The production and accumulation of secondary metabolites are influenced by many environmental factors including light characteristics.

For horticultural production, colored leaves, flowers, or fruits are distinctive and desirable; thus, maximizing pigmentation is important. Plant coloration is mainly provided by the accumulation of flavonoids (including anthocyanidins), carotenoids, and betalains (Tanaka et al., 2008). Flavonoid synthesis is sensitive to change in light quality; blue and ultraviolet wavelengths are most effective in promoting flavonoid accumulation by upregulating the expression of pathway genes (Zoratti et al., 2014). Blue light, via the cryptochromes and phototropins, drives the synthesis of anthocyanin (Kadomura-Ishikawa et al., 2013; Zhang et al., 2018). Supplemental blue light increases the anthocyanin and carotenoid concentration, whereas supplemental far-red light decreases anthocyanin, carotenoid, and chlorophyll concentration in comparison with white light control in lettuce ( $\mathrm{Li}$ and Kubota, 2009). Carotenoid concentration was found to be greater in buckwheat seedlings grown under white light than in those grown with pure blue or red light (Tuan et al., 2013). Chlorophyll pigments mainly contribute to the green leaf color. Light quality affects the biosynthesis of chlorophyll and blue light is known to promote the accumulation of chlorophyll (see Photosynthesis section).

Photosynthesis inevitably generates reactive oxygen species from the electron transport activities of chloroplasts and the respiration of mitochondria. Secondary metabolic compounds, such as carotenoids, phenolic compounds, ascorbate, and glutathione, are active in scavenging redox stress (Nisar et al., 2015). Phenolic and flavonoid com- pounds are widely existing plant secondary metabolites that enable the plants to adapt to both biotic and abiotic stresses (Ouzounis et al., 2014). Most flavonoids, such as ascorbate and a-tocopherol, are well-known antioxidants (Hernández et al., 2009). Jeong et al. (2012) investigated the influence of light quality on polyphenol biosynthesis in Chrysanthemum, and nine polyphenols were characterized, of which concentration was highest under green or red light, indicating promotional effects for polyphenol biosynthesis. Blue light was found to increase the oil content compared with white light treatments in basil leaves (Amaki et al., 2011). Also, light intensity influences the biosynthesis of secondary metabolites, with increasing light intensity resulting in an increase in the production of polyphenols in herbs (Manukyan, 2013). It is, therefore, important to provide sufficient light to drive photosynthesis, and alter light quality/intensity in horticultural production to simulate various biosynthetic pathways and maximize production of desirable compounds, to produce plants with demanding characteristics.

\section{Conclusions and Future Perspectives}

Greenhouse horticulture in high latitudes relies on supplemental lighting during winter to achieve high-quality production. In horticultural production and research, there is a growing interest in using LED as supplementary lighting to improve light usage efficiency. Sole-source LED could be used as the light source for indoor growing of relatively small size plants in multilayer vertical farming systems; thus, manipulating light characteristics for the regulation of plant growth and development is practicable. Based on the knowledge gained, optimization of the $\mathrm{RB}$ ratio for the horticulture industry needs different light combination strategies. The mechanisms underlying the physiology and metabolism under the influence of different light spectra still need to be studied with respect to solely LED light combinations.

LED research is still at the start of its potential, now focusing mainly on $\mathrm{R}$ and $\mathrm{B}$ combinations. However, in addition to red and blue spectra, other spectra are still interesting for research purpose. For example, green light is reported to reduce the negative effects caused by continuous lighting. Furthermore, application of ultraviolet light in production, as a component of solar radiation, exerts a wide range of physiological responses in plants, which are still open for further research.

\section{Literature Cited}

Abidi, F., T. Girault, O. Douillet, G. Guillemain, G. Sintes, M. Laffaire, H. Ben Ahmed, S. Smiti, L. Huché-Thélier, and N. Leduc. 2013. Blue light effects on rose photosynthesis and photomorphogenesis. Plant Biol. 15:67-74.

Ahmad, M. and A.R. Cashmore. 1993. HY4 gene of $A$. thaliana encodes a protein with charactteristics of a blue-light photoreceptor. Nature $361: 162-166$
Amaki, W., N. Yamazaki, M. Ichimura, and H. Watanabe. 2011. Effects of light quality on the growth and essential oil content in Sweet basil. Acta Hort. 907:91-94.

Arena, C., T. Tsonev, D. Doneva, V. De Micco, M. Michelozzi, C. Brunetti, M. Centritto, S. Fineschi, V. Velikova, and F. Loreto. 2016. The effect of light quality on growth, photosynthesis, leaf anatomy and volatile isoprenoids of a monoterpene-emitting herbaceous species (Solanum lycopersicum L.) and an isoprene-emitting tree (Platanus orientalis L.). Environ. Exp. Bot. 130:122-132.

Briggs, W.R. and J.M. Christie. 2002. Phototropins 1 and 2: Versatile plant blue-light receptors. Trends Plant Sci. 7:204-210.

Brouwer, B., P. Gardeström, and O. Keech. 2014. In response to partial plant shading, the lack of phytochrome A does not directly induce leaf senescence but alters the fine-tuning of chlorophyll biosynthesis. J. Expt. Bot. 65:40374049.

Brown, B.A., C. Cloix, G.H. Jiang, E. Kaiserli, P. Herzyk, D.J. Kliebenstein, and G.I. Jenkins. 2005. A UV-B-specific signaling component orchestrates plant UV protection. Proc. Natl. Acad. Sci. USA 102:18225-18230.

Casal, J.J. 2000. Phytochromes, cryptochromes, phototropin: Photoreceptor interactions in plants. Photochem. Photobiol. 71:1-11.

Cashmore, A.R., J.A. Jarillo, Y-J. Wu, and D. Liu. 1999. Cryptochromes: Blue light receptors for plants and animals. Science 284:760-765.

D’Souza, C., H.G. Yuk, G.H. Khoo, and W. Zhou. 2015. Application of light-emitting diodes in food production, postharvest preservation, and microbiological food safety. Compr. Rev. Food Sci. Food Saf. 14:719-740.

Davis, P.A. and C. Burns. 2016. Photobiology in protected horticulture. Food Energy Secur. 5:223-238.

de Carbonnel, M., P. Davis, M.R.G. Roelfsema, S.-i. Inoue, I. Schepens, P. Lariguet, M. Geisler, K.-i. Shimazaki, R. Hangarter, and C. Fankhauser. 2010. The Arabidopsis PHYTOCHROME KINASE SUBSTRATE2 protein is a phototropin signaling element that regulates leaf flattening and leaf positioning. Plant Physiol. 152:1391-1405.

Dieleman, J.A., P.H.B. De Visser, and P.C.M Vermeulen. 2016. Reducing the carbon footprint of greenhouse grown crops: Re-designing LED-based production systems. Acta Hort. 1134:395-402.

Fankhauser, C. and J. Chory. 1997. Light control of plant development. Annu. Rev. Cell Dev. Biol. 13:203-229.

Folta, K.M. and S.D. Carvalho. 2015. Photoreceptors and control of horticultural plant traits. HortScience 50:1274-1280.

Folta, K.M. and K.S. Childers. 2008. Light as a growth regulator: Controlling plant biology with narrow-bandwidth solid-state lighting systems. HortScience 43:1957-1964.

Furuya, M. and E. Schäfer. 1996. Photoperception and signalling of induction reactions by different phytochromes. Trends Plant Sci. 1:301307.

Galvão, V.C. and C. Fankhauser. 2015. Sensing the light environment in plants: Photoreceptors and early signaling steps. Curr. Opin. Neurobiol. 34:46-53.

Gitz, D.C., L. Liu-Gitz, S.J. Britz, and J.H. Sullivan. 2005. Ultraviolet-B effects on stomatal density, water-use efficiency, and stable carbon isotope discrimination in four glasshouse-grown soybean (Glyicine max) cultivars. Environ. Exp. Bot. 53:343-355. 
Goto, E. 2012. Plant production in a closed plant factory with artificial lighting. Acta Hort. 956:37-49.

Gu, J.w., J. Liu, Y.j. Xue, X. Zang, and X.-z. Xie. 2011. Functions of phytochrome in rice growth and development. Rice Sci. 18:231-237.

Haliapas, S., T.A. Yupsanis, T.D. Syros, G. Kofidis, and A.S. Economou. 2008. Petunia x hybrida during transition to flowering as affected by light intensity and quality treatments. Acta Physiol. Plant. 30:807-815.

Hamdani, S., N. Khan, S. Perveen, M. Qu, J. Jiang, Govindjee and X.G. Zhu. 2019. Changes in the photosynthesis properties and photoprotection capacity in rice (Oryza sativa) grown under red, blue, or white light. Photosynth. Res. 139:107121.

Hernández, I., L. Alegre, F. Van Breusegem, and S. Munné-Bosch. 2009. How relevant are flavonoids as antioxidants in plants? Trends Plant Sci. 14:125-132.

Heung, K.M., S.Y. Park, W.K. Yong, and S.K. Chan. 2006. Growth of Tsuru-rindo (Tripterospermum japonicum) cultured in vitro under various sources of light-emitting diode (LED) irradiation. J. Plant Biol. 49:174-179.

Hirose, F., T. Shinomura, T. Tanabata, H. Shimada, and M. Takano. 2006. Involvement of rice cryptochromes in de-etiolation responses and flowering. Plant Cell Physiol. 47:915-925.

Hiyama, A., A. Takemiya, S. Munemasa, E. Okuma, N. Sugiyama, Y. Tada, Y. Murata, and K.I. Shimazaki. 2017. Blue light and $\mathrm{CO}_{2}$ signals converge to regulate light-induced stomatal opening. Nat. Commun. 8:1-12.

Hogewoning, S.W., G. Trouwborst, H. Maljaars, H. Poorter, W. van Ieperen, and J. Harbinson. 2010. Blue light dose-responses of leaf photosynthesis, morphology, and chemical composition of Cucumis sativus grown under different combinations of red and blue light. J. Expt. Bot. 61:3107-3117.

Hughes, J. 2013. Phytochrome cytoplasmic signaling. Annu. Rev. Plant Biol. 64:377-402.

Islam, M.A., G. Kuwar, J.L. Clarke, D.R. Blystad, H.R. Gislerød, J.E. Olsen, and S. Torre. 2012. Artificial light from light emitting diodes (LEDs) with a high portion of blue light results in shorter poinsettias compared to high pressure sodium (HPS) lamps. Scientia Hort. 147:136143.

Izzo, L.G., C. Arena, V. De Micco, F. Capozzi, and G. Aronne. 2019. Light quality shapes morphofunctional traits and pigment content of green and red leaf cultivars of Atriplex hortensis. Scientia Hort. 246:942-950.

Jeong, S.W., S. Park, J.S. Jin, O.N. Seo, G.S. Kim, Y.H. Kim, H. Bae, G. Lee, S.T. Kim, W.S. Lee, and S.C. Shin. 2012. Influences of four different light-emitting diode lights on flowering and polyphenol variations in the leaves of chrysanthemum (Chrysanthemum morifolium). J. Agr. Food Chem. 60:9793-9800.

Jiao, Y., O.S. Lau, and X.W. Deng. 2007. Lightregulated transcriptional networks in higher plants. Nat. Rev. Genet. 8:217-230.

Johnson, M.P. 2016. Photosynthesis. Essays Biochem. 60:255-273.

Kadomura-Ishikawa, Y., K. Miyawaki, S. Noji, and A. Takahashi. 2013. Phototropin 2 is involved in blue light-induced anthocyanin accumulation in Fragaria $\times$ ananassa fruits. J. Plant Res. 126:847-857.

Kaiser, E., T. Ouzounis, H. Giday, R. Schipper, E. Heuvelink, and L.F.M. Marcelis. 2019. Adding blue to red supplemental light increases biomass and yield of greenhouse-grown tomatoes, but only to an optimum. Front. Plant Sci. 9:111.

Kaiserli, E. and G. Jenkins. 2007. UV-B promotes rapid nuclear translocation of the Arabidopsis UV-B-specific signaling component UVR8 and activates its function in the nucleus. The Plant Cell 19(8):2662-2673.

Kami, C., S. Lorrain, P. Hornitschek, and C. Fankhauser. 2010. Light-regulated plant growth and development. Curr. Top. Dev. Biol. 91:29-66.

Kasahara, M., T. Kagawa, K. Oikawa, N. Suetsugu, M. Miyao, and M. Wada. 2002. Chloroplast avoidance movement reduces photodamage in plants. Nature 420:829-832.

Kim, H.J., M.Y. Lin, and C.A. Mitchell. 2019. Light spectral and thermal properties govern biomass allocation in tomato through morphological and physiological changes. Environ. Exp. Bot. 157:228-240.

Kleine, T., P. Lockhart, and A. Batschauer. 2003 An Arabidopsis protein closely related to Synechocystis cryptochrome is targeted to organelles. Plant J. 35:93-103.

Kliebenstein, D.J., J.E. Lim, L.G. Landry, and R.L. Last. 2002. Arabidopsis UVR8 regulates ultraviolet-B signal transduction and tolerance and contains sequence similarity to human regulator of chromatin condensation. Plant Physiol. 130:234-243.

Kong, S.G. and M. Wada. 2016. Molecular basis of chloroplast photorelocation movement. J. Plant Res. 129:159-166.

Lariguet, P. and C. Fankhauser. 2004. Hypocotyl growth orientation in blue light is determined by phytochrome A inhibition of gravitropism and phototropin promotion of phototropism. Plant J. 40:826-834.

Li, H., C. Tang, and Z. Xu. 2013. The effects of different light qualities on rapeseed (Brassica napus L.) plantlet growth and morphogenesis in vitro. Scientia Hort. 150:117-124.

Li, Q. and C. Kubota. 2009. Effects of supplemental light quality on growth and phytochemicals of baby leaf lettuce. Environ. Exp. Bot. 67:5964.

Lin, C. and D. Shalitin. 2003. Cryptochrome structure and signal transduction. Annu. Rev. Plant Biol. 54:469-496.

Liu, H., B. Liu, C. Zhao, M. Pepper, and C. Lin. 2012. The action mechanisms of plant cryptochromes. Trends Plant Sci. 16:684-691.

Liu, M., Z. Xu, S. Guo, C. Tang, X. Liu, and X. Jao. 2014. Evaluation of leaf morphology, structure and biochemical substance of balloon flower (Platycodon grandiflorum (Jacq.) A. DC.) plantlets in vitro under different light spectra. Scientia Hort. 174:112-118.

Liu, Y., T. Wang, S. Fang, M. Zhou, and J. Qin. 2018. Responses of morphology, gas exchange, photochemical activity of photosystem II, and antioxidant balance in Cyclocarya paliurus to light spectra. Front. Plant Sci. 9:1-15.

Lobiuc, A., V. Vasilache, O. Pintilie, T. Stoleru, M. Burducea, M. Oroian, and M.M. Zamfirache. 2017. Blue and red LED illumination improves growth and bioactive compounds contents in acyanic and cyanic ocimum Basilicum L. Microgreens. Molecules 22, doi: 10.3390/molecules22122111.

Luesse, D.R., S.L. Deblasio, and R.P. Hangarter. 2010. Integration of phot 1 , phot2, and PhyB signalling in light-induced chloroplast movements. J. Expt. Bot. 61:4387-4397.

Manukyan, A. 2013. Effects of PAR and UV-B radiation on herbal yield, bioactive compounds and their antioxidant capacity of some medicinal plants under controlled environmental conditions. Photochem. Photobiol. 89:406-414.

Mawphlang, O.I.L. and E.V. Kharshiing. 2017. Photoreceptor mediated plant growth responses: Implications for photoreceptor engineering toward improved performance in crops. Front. Plant Sci. 8:1-14.

Mazza, C.A. and C.L. Ballaré. 2015. Photoreceptors UVR8 and phytochrome B cooperate to optimize plant growth and defense in patchy canopies. New Phytol. 207:4-9.

McCree, K.J. 1971. The action spectrum, absorptance and quantum yield of photosynthesis in crop plants. Agr. Meteorol. 9:191-216.

Mitchell, C., A-J. Both, M. Bourget, J. Burr, C. Kubota, R. Lopez, R. Morrow, and E. Runkle. 2012. LEDs: The future of greenhouse lighting! Chron. Hort. 52:1-9.

Nanya, K., Y. Ishigami, S. Hikosaka, and E. Goto. 2012. Effects of blue and red light on stem elongation and flowering of tomato seedlings. Acta Hort. 956:261-266.

Naznin, M., M. Lefsrud, V. Gravel, and M. Azad. 2019. Blue light added with red LEDs enhance growth characteristics, pigments content, and antioxidant capacity in lettuce, spinach, kale, basil, and sweet pepper in a controlled environment. Plants 8:93.

Nelson, J.A. and B. Bugbee. 2014. Economic analysis of greenhouse lighting: Light emitting diodes vs. high intensity discharge fixtures. PLoS One 9, doi: 10.1371/journal.pone.0099010.

Nisar, N., L. Li, S. Lu, N.C. Khin, and B.J. Pogson. 2015. Carotenoid metabolism in plants. Mol. Plant 8:68-82.

O'Carrigan, A., E. Hinde, N. Lu, X.Q. Xu, H. Duan, G. Huang, M. Mak, B. Bellotti, and Z.H. Chen. 2014. Effects of light irradiance on stomatal regulation and growth of tomato. Environ. Exp. Bot. 98:65-73.

Oda, A., T. Narumi, T. Li, T. Kando, Y. Higuchi, K. Sumitomo, S. Fukai, and T. Hisamatsu. 2012. CsFTL3, a chrysanthemum FLOWERING LOCUS T-like gene, is a key regulator of photoperiodic flowering in chrysanthemums. J. Expt. Bot. 63:1461-1477.

Ouzounis, T., X. Fretté, E. Rosenqvist, and C.O. Ottosen. 2014. Spectral effects of supplementary lighting on the secondary metabolites in roses, chrysanthemums, and campanulas. J. Plant Physiol. 171:1491-1499.

Park, Y. and E.S. Runkle. 2018. Far-red radiation and photosynthetic photon flux density independently regulate seedling growth but interactively regulate flowering. Environ. Exp. Bot. 155:206-216.

Pillitteri, L.J. and K.U. Torii. 2012. Mechanism of stomatal development. Annu. Rev. Plant Biol. 63:12.112.4.

Piovene, C., F. Orsini, S. Bosi, R. Sanoubar, V. Bregola, G. Dinelli, and G. Gianquinto. 2015. Optimal red: Blue ratio in led lighting for nutraceutical indoor horticulture. Scientia Hort. 193:202-208.

Poudel, P.R., I. Kataoka, and R. Mochioka. 2008. Effect of red- and blue-light-emitting diodes on growth and morphogenesis of grapes. Plant Cell Tissue Organ Cult. 92:147-153.

Quail, P.H. 1997. An emerging molecular map of the phytochromes. Plant Cell Environ. 20:657665 .

Riikonen, J., N. Kettunen, M. Gritsevich, T. Hakala, L. Särkkä, and R. Tahvonen. 2016. Growth and development of Norway spruce and Scots pine seedlings under different light spectra. Environ. Exp. Bot. 121:112-120.

Rizzini, L., J.J. Favory, C. Cloix, D. Faggionato, A. O’Hara, E. Kaiserli, R. Baumeister, E. Schafer, 
F. Nagy, G.I. Jenkins, and R. Ulm. 2011. Perception of UV-B by the Arabidopsis UVR8 protein. Science 332:103-106.

Sager, J.C. and C. McFarlane. 1997. Radiation. Plant growth chamber handbook. North Central Region Research Publication No. 340, Iowa Agriculture and Home Economics Experiment Station Special Report no. 99. Iowa State Univ. Press, Ames, IA.

Samuolienè, G., A. Brazaityte, and A. Urbonavičiūtè. 2010. The effect of red and blue light component on the growth and development of frigo strawberries. Zemdirbyste-Agriculture 97:99-104.

Shengxin, C., L. Chunxia, Y. Xuyang, C. Song, J. Xuelei, L. Xiaoying, X. Zhigang, and G. Rongzhan. 2016. Morphological, photosynthetic, and physiological responses of rapeseed leaf to different combinations of red and blue lights at the rosette stage. Front. Plant Sci. 7:112.

Shimazaki, K., M. Doi, S.M. Assmann, and T. Kinoshita. 2007. Light regulation of stomatal movement. Annu. Rev. Plant Biol. 58:219-247.

Shimizu, H., Z. Ma, M. Douzono, S. Tazawa, E.S. Runkle, and R.D. Heins. 2006. Blue light inhibits stem elongation of chrysanthemum. Acta Hort. 711:363-367.

Shinomura, T., A. Nagatani, H. Hanzawa, M. Kubota, M. Watanabe, and M. Furuya. 1996. Action spectra for phytochrome A- and Bspecific photoinduction of seed germination in Arabidopsis thaliana. Proc. Natl. Acad. Sci. USA 93:8129-8133.

Son, K.H. and M.M. Oh. 2013. Leaf shape, growth, and antioxidant phenolic compounds of two lettuce cultivars grown under various combinations of blue and red light-emitting diodes. HortScience 48:988-995.

Sood, S., V. Gupta, and B.C. Tripathy. 2005. Photoregulation of the greening process of wheat seedlings grown in red light. Plant Mol. Biol. 59:269-287.

Suetsugu, N. and M. Wada. 2007. Chloroplast photorelocation movement mediated by photo- tropin family proteins in green plants. Biol. Chem. 388:927-935.

Sullivan, J.A. and X.W. Deng. 2003. From seed to seed: The role of photoreceptors in Arabidopsis development. Dev. Biol. 260:289-297.

Tähkämö, L. and H.E. Dillon. 2014. Handbook of advanced lighting technology. Handb. Adv. Light. Sect. 1-18. <https://doi.org/10.1007/ 978-3-319-00295-8_41-1>.

Takahashi, S. and M.R. Badger. 2011. Photoprotection in plants: A new light on photosystem II damage. Trends Plant Sci. 16:53-60.

Tanaka, A. and R. Tanaka. 2006. Chlorophyll metabolism. Curr. Opin. Plant Biol. 9:248-255.

Tanaka, Y., N. Sasaki, and A. Ohmiya. 2008. Biosynthesis of plant pigments: Anthocyanins, betalains and carotenoids. Plant J. 54:733-749.

Tuan, P.A., A.A. Thwe, Y.B. Kim, J.K. Kim, S.J. Kim, S. Lee, S.O. Chung, and S.U. Park. 2013 Effects of white, blue, and red light-emitting diodes on carotenoid biosynthetic gene expression levels and carotenoid accumulation in sprouts of tartary buckwheat (Fagopyrum tataricum Gaertn.). J. Agr. Food Chem. 61:12356-12361.

Wang, F.F., H.L. Lian, C.Y. Kang, and H.Q. Yang. 2010. Phytochrome B is involved in mediating red light-induced stomatal opening in Arabidopsis thaliana. Mol. Plant 3:246-259.

Wang, J., W. Lu, Y. Tong, and Q. Yang. 2016. Leaf morphology, photosynthetic performance, chlorophyll fluorescence, stomatal development of lettuce (Lactuca sativa L.) exposed to different ratios of red light to blue light. Front. Plant Sci. 7:250.

Wang, X., Q. Wang, P. Nguyen, and C. Lin. 2014. Cryptochrome-mediated light responses in plants. 1st ed. The enzymes. Elsevier Inc. $<$ https://doi.org/10.1016/B978-0-12-8019221.00007-5>.

Wang, X.Y., X.M. Xu, and J. Cui. 2015. The importance of blue light for leaf area expansion, development of photosynthetic apparatus, and chloroplast ultrastructure of Cucumis sat- ivus grown under weak light. Photosynthetica 53:213-222.

Wang, Y., S.A. Maruhnich, M.H. Mageroy, J.R. Justice, and K.M. Folta. 2013. Phototropin 1 and cryptochrome action in response to green light in combination with other wavelengths. Planta 237:225-237.

Wright, S.W. and J.D. Shearer. 1984. Rapid extraction and high-performance liquid chromatography of chlorophylls and carotenoids from marine phytoplankton. J. Chromatography 294:281-295.

Yoneda, Y., H. Nakashima, J. Miyasaka, K. Ohdoi, and H. Shimizu. 2017. Impact of blue, red, and far-red light treatments on gene expression and steviol glycoside accumulation in Stevia rebaudiana. Phytochemistry 137:57-65.

Yorio, N.C., G.D. Goins, H.R. Kagie, R.M. Wheeler, and J.C. Sager. 2001. Improving spinach, radish, and lettuce growth under red light-emitting diodes (LEDs) with blue light supplementation. HortScience 36:380-383.

Yoshida, H., S. Hikosaka, E. Goto, H. Takasuna, and T. Kudou. 2012. Effects of light quality and light period on flowering of everbearing strawberry in a closed plant production system. Acta Hort. 956:107-112.

Zhang, Y., L. Jiang, Y. Li, Q. Chen, Y. Ye, Y. Zhang, Y. Luo, B. Sun, X. Wang, and H. Tang. 2018. Effect of red and blue light on anthocyanin accumulation and differential gene expression in strawberry (Fragaria $\times$ ananassa). Molecules 23:1-17.

Zhiyu, M., H. Shimizu, S. Moriizumi, M. Miyata, M. Douzono, and S. Tazawa. 2007. Effect of light intensity, quality and photoperiod on stem elongation of chrysanthemum cv. Reagan. Environ. Control Biol. https://doi.org/10.2525/ ecb. 45.19

Zoratti, L., K. Karppinen, A. Luengo Escobar, H. Häggman, and L. Jaakola. 2014. Light-controlled flavonoid biosynthesis in fruits. Front. Plant Sci. 5:1-16. 